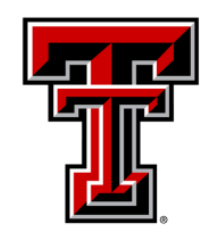

TEXAS TECH UNIVERSITY

Libraries"

\title{
Enhancing ACademic Library Performance Through Positive PSYCHOLOGY
}

\section{The Texas Tech community has made this publication openly available. Please share how this access benefits you. Your story matters to us.}

\begin{tabular}{|l|l|}
\hline Citation & $\begin{array}{l}\text { Quinn, B. (2005, February). Enhancing Academic Library } \\
\text { Performance Through Positive Psychology. Journal of Library } \\
\text { Administration, 42(1), 79-101. } \\
\text { https://doi.org/10.1300/J111v42n01 05 }\end{array}$ \\
\hline Citable Link & $\underline{\text { http://hdl.handle.net/2346/482 }}$ \\
\hline Terms of Use & $\underline{\text { CC-BY }}$ \\
\hline
\end{tabular}


A new paradigm is emerging in the field of psychology that may have important implications for academic librarianship. In recent years and indeed for most of the twentieth century, psychology has been preoccupied with pathology, mental illness, and with discovering ways of treating people with emotional problems. This focus on the negative was fueled by several historical factors, among them Freud and his deterministic emphasis on neuroses, and decades later, by the formation of the National Institute of Mental Health which despite its name, awarded grants primarily for the study of mental illness.

In the last few years, a small but growing number of psychologists have come to the conclusion that the field of psychology has placed too much emphasis on the negative aspects of human behavior. They believe it is time for psychology to turn its attention to the study of positive human qualities. These qualities include such positive mental states as optimism, happiness, joy, altruism, creativity, and hope. This new-found emphasis on optimal human functioning stands in sharp contrast to the emphasis on emotional and behavioral dysfunction that has characterized the field of psychology since the turn of the century.

Although positive psychology may sound vaguely reminiscent of the humanistic psychology movement that Carl Rogers and Abraham Maslow spearheaded in the 1960's, positive psychologists believe that there is an important difference.1 Humanistic psychology was not based on empirical studies, but positive psychology has a solid foundation in scientifically valid surveys and experiments. Most of the psychologists involved in the movement have academic affiliations and possess solid scholarly credentials. This rapidly emerging subfield of psychology is very well organized and has 
held several conferences devoted exclusively to the topic. The conferences have drawn prominent social scientists from around the country, not only in psychology but also sociology, communications, economics, and other fields.

\section{Positive Psychology in the Workplace}

Several positive psychology conferences have been sponsored by the Gallup Corporation. Gallup has spent decades conducting survey research in an effort to determine what makes workers more productive in the workplace. The Gallup Corporation plans to develop further studies based on the findings of these conferences. 2

Gallup researchers have conducted hundreds of studies involving focus groups covering a broad cross-section of industries in an effort to study what it is that makes individuals and groups productive in organizations. What they found is that highperforming companies have employees with very positive emotional states. These employees are characterized by Gallup researchers as demonstrating high amounts of interest, caring, and joy in their work. Managers in these organizations foster positive emotions in employees by paying attention to their needs and recognizing their unique contributions. Meeting the basic needs of employees are met, this frees them to devote maximum attention and cognition to their work and to achieving the goals of the organization. Workers who regularly receive positive feedback about their contributions are motivated to think about how they can accomplish even more for the organization.

Several researchers conducted a meta-analysis of the Gallup studies to determine what generalizations could be drawn from the data. One of the most important findings was that there is a relationship between how well employee needs are met and the level of 
customer satisfaction and loyalty achieved by the organization. There is also a relationship between meeting employee needs and employee retention and turnover. The researchers defined employee needs to include such basic needs as having clear expectations and adequate tools to do their work as well as higher needs like enjoying a good person/job fit, having managers who care and listen, fellow employees committed to doing quality work, and opportunities to learn and develop on the job.3 The researchers concluded their study by noting that negative reinforcement may help the organization in the short run but compromise it over the long term. Negative emotions like depression hinder thinking processes like complex cognition while positive emotions enhance an employee's ability to process information and act creatively. Organizations that foster positive emotions enhance employee engagement which in turn makes them more effective and profitable.

\section{Accentuating the Negative in Academic Libraries}

Concepts, trends and practices in academic library administration do not always emerge from the field of librarianship itself. They are often imported or derived from other fields. These fields include business administration, organizational behavior, and management. Trends in library management often reflect current practices in the business world, and this has become increasingly evident in recent years. The growing emphasis on accountability, evaluation, and quality service in academic libraries all have their origins in the business sector.

The management literature tends to emphasize many negative aspects of the workplace. Much of it is problem-based and tries to focus on what is wrong with 
employees and on how to identify and correct weaknesses in employee performance and behaviors. The kinds of topics that are frequently found in management literature, such as reluctance to change, stress, coping, burnout, interpersonal conflict, performance and motivational problems, and communication difficulties, are all equally prevalent in the library literature.4 If the literature of academic librarianship is any indication, academic libraries these days are not institutions that exhibit a characteristically positive orientation.

There are indications that the negative emphasis may be beginning to change, at least with regard to the field of management and organizational behavior. Fred Luthans, a professor of management at the University of Nebraska, has proposed a new approach to management that he refers to as positive organizational behavior. Professor Luthans draws on the emerging positive psychology movement to suggest that management and organizational scholars need to rethink their approach and begin to focus on the psychological strengths of workers. Doing so could lead to more effective management and improved organizational outcomes. According to Luthans, there are six psychological traits that can be cultivated in administrators and in staff that will lead to positive organizational behavior: self-efficacy, hope, optimism, subjective well-being, emotional intelligence, and resilience. 5 It would be helpful to take a closer look at each of these traits in order to understand how they might apply to academic libraries.

\section{$\underline{\text { Self-Efficacy }}$}

Self-efficacy is a psychological construct introduced by Albert Bandura in the 1970s that refers to a person's belief that he or she has the ability to act effectively to 
bring about a desired outcome or to prevent an undesired outcome from occurring. It constitutes an important aspect of positive psychology because unless one believes positively that one can affect a particular end result in a particular situation, one has little motivation to act. The more strongly a librarian believes that he or she is capable of achieving a particular end, the more motivated the person will be to achieve what he or she set out to do. Librarians with high self-efficacy expect favorable outcomes and are willing to expend extra effort to bring them about. 6

Those who possess high self-efficacy beliefs are also more likely to persevere in the face of obstacles or setbacks. A librarian with weak self-efficacy beliefs would be more inclined to decrease efforts, slack off, or give up altogether. The same person with strong self-efficacy beliefs would be much more likely to double their efforts in an attempt to overcome the problem. Any failures encountered would be perceived as temporary setbacks rather than permanent defeat. Librarians with strong beliefs in selfefficacy will also be more likely to set higher goals for themselves.

Self-efficacy beliefs also influence an individual's ability to solve problems and make decisions. Librarians high in self-efficacy possess strong convictions that they have the ability to solve problems and thus are much more likely to approach problematic situations head on rather than avoid them. Highly self-efficacious individuals are more effective at problem solving than those low in self-efficacy. High self-efficacy librarians make better use of their cognitive abilities by utilizing a task-diagnostic approach and working persistently to solve the problem. Individuals who are low in self-efficacy, by contrast, tend to take a self-diagnostic approach and focus on their perceived shortcomings and deficiencies.7 This self-absorption serves as a distraction and drains 
the librarian's attention and effort away from the problem solving process, rendering them less capable of arriving at a solution.

Another way in which self-efficacy beliefs play an important role in the workplace is the effect they have on a worker's health. Individuals who are low in selfefficacy experience higher levels of emotional and physiological stress from perceived workloads than high self-efficacy individuals. Interestingly, librarians who are high in self-efficacy feel more stress when they perceive a lack of challenge and an inability to exercise control over their work stemming from organizational constraints. Librarians who are low in self-efficacy and who experience continual occupational stress are more vulnerable to symptoms of burnout. These symptoms include psychological and physical exhaustion, disengagement from patrons, the absence of a sense of personal accomplishment, and cynicism about one's work.8

In an area of particular importance to academic libraries, self-efficacy beliefs have been shown to affect the receptivity of both administrators and staff to new technology. This suggests that librarians who possess high self-efficacy beliefs are less likely to approach innovations in technology with feelings of self-doubt or inadequacy. The stronger a librarian's efficacy beliefs related to mastering computers, the more quickly he or she will adopt new technology.9 Those with low self-efficacy are more likely to be late adopters or engage in avoidance behavior.

$\underline{\text { Increasing Self-Efficacy in the Academic Library Workplace }}$

Given that high self-efficacy appears to result in increased motivation, perseverance, problem solving, decision-making, resilience, and technological 
receptiveness in library staff, what can be done to foster self-efficacy in academic libraries? Albert Bandura, the psychologist who first introduced the self-efficacy concept, has outlined a process called guided mastery, which his research suggests is the most effective means of cultivating self-efficacy in individuals.10 The process consists of three phases: instructive modeling, guided practice, and transfer training.

Instructive modeling involves taking complex skills like library instruction or reference interviewing and breaking them down into sub-skills which can then be modeled on videotape. Breaking complex skills down makes them easier to learn. The video should include explanatory narrative as the skills are being modeled, along with brief summaries of the main points or concepts. If the modeling is to enhance the viewer's sense of personal efficacy, care must be chosen in selecting the model. The more the model is perceived to be similar to the viewer, the better the skills will be learned. Similarly, the more the types of problems encountered and the situations to which the skills apply are similar to the viewer's, the better they will be learned.

In the next phase, guided practice, learners should be allowed to practice their skills in simulated, role rehearsal situations. Learning will be enhanced through combining cognitive and behavioral rehearsal. Cognitive rehearsal requires the learner to mentally rehearse how he or she will apply their skills to particular situations. Feedback should be provided either by videotaping learners or by comments from observers. It is very important that the feedback be positive, constructive, and supportive if self-efficacy is to be enhanced. The use of corrective modeling, in which poorly learned sub-skills are further modeled followed by further rehearsal by learners, tends to result in the greatest improvements. 
The third phase is called transfer training. Learners are first allowed to try out their new skills in actual work situations that are likely to result in a good outcome. Performing the activity with a more experienced partner may help initially. Then gradually as they gain proficiency and a sense of self-confidence, they should be allowed to take on more complex assignments and perform them alone. This seldom happens in actual library practice for a variety of reasons. Experienced staff are frequently overworked and seldom have time to devote to working with new librarians. Staffing shortages often mean poorly trained or inexperienced librarians are thrust into new situations without time for adequate practice or preparation. This "sink or swim" ethos creates stress in the librarian who is trying to learn and results in inferior service to library users. It should also be added that cultivating self-efficacy in academic libraries is not limited to training situations. Supervisors and particularly administrators need to serve as positive role models for their staff by providing positive feedback and constructive evaluations. Academic library administrators who do little to instill selfefficacy in their staff ultimately compromise employee performance, perseverance, and resilience. 11

\section{Hope}

Hope is a belief that one can bring about desirable outcomes by finding certain means or pathways to achieve them. It differs from self-efficacy which refers primarily to more specific situations, while hope may be thought of as a more enduring general belief that is sustainable across situations. Psychologists have found that some people are 
skilled at generating pathways to achieve their goals, and that those who are most hopeful are the most resourceful at creating alternate pathways. 12

The presence or absence of hope in people may have an important effect on the way they perform. Studies of college athletes have found that they have higher levels of hope than non-athletes. The higher an athlete's level of hope the more likely the athlete is to have better grades and cumulative GPA. The combination of academic pressure and collegiate competition requires college athletes not only to be very goal directed but also to be hopeful thinkers. Focusing on goals serves to provide both a focus and a source of motivation.13 When obstacles appear, the most successful athletes are able to develop different pathways to achieving their ends.

Performance on the job is also affected by the level of hope that employees possess. In order for workers to deliver high quality service, they must be in good health. A recent study of 158 hospital nurses found that there is a significant correlation between a nurse's level of hope and his or her perception of health. This suggested to researchers that even in a stressful occupation like nursing, it is possible to have a positive response and that a positive outlook has an important relationship to the health of employees. One interesting finding of the study was that nurses who worked under the most stressful conditions in intensive care had higher levels of hope than non-ICU nurses and reported experiencing lower levels of stress.14

Another study compared the levels of hopefulness of professionals in the field of social work. The authors of the study investigated whether case workers who had high hopes regarding their clients experienced benefits from these beliefs. They divided their sample into two groups: those who expected their clients to show demonstrable 
improvement and gratitude and those with a less hopeful perspective. Case workers who were less hopeful believed that they would achieve only limited improvement in their clients. The researchers theorized that social workers who were most hopeful about their clients would be more vulnerable to job dissatisfaction and burnout the longer they spent working in the field because of excessive paperwork, bureaucracy, case loads, and the realization of their own limited ability to help clients. The opposite, however, proved to be true. The case workers with the highest levels of hope proved to be more successful and to remain in the field longer. The authors reasoned that high levels of hope allowed them to cope better with stress. It provided them with higher energy levels so that they could be more productive and achieve more with clients.15 The higher expectations that they held for their clients may have had a positive effect on the client's performance.

These studies suggest that it is in the best interests of academic library administrators to enhance hope among employees. Hope can be generated by establishing meaningful goals and then making sure that employees have sufficient resources to meet those goals. Additionally, one of the most important ingredients in generating hope in academic libraries may be information. In the study of nurses, the factor with the strongest negative correlation to hope was role ambiguity. Administrators need to do as much as possible to eliminate role ambiguity. Librarians who do not understand what is expected of them, who are uncertain how to meet expectations, or who do not grasp the consequences of failing to meet expectations are most likely to be least hopeful about their work. Another way to reduce role ambiguity is to make sure relationships between librarians and their supervisors are supportive and open. 
Administrators should strive to make themselves available to librarians and communicate with them.

The relationship between hope and health suggests that control may be related to hope because of the close affinity between control and health. Researchers have discovered that employee health and perceptions of health are correlated with feelings of personal control.17 Allowing professional librarians the flexibility to conduct their work and meet their goals by utilizing their own preferred methods and strategies is important for engendering a sense of control and countering feelings of helplessness that can eventually lead to hopelessness. In many instances, librarians may be better at devising means of reaching goals than managers, because they are closer to their jobs.

Perhaps the most interesting study of hope was conducted in the spring of 2000 , when $\underline{\text { Success }}$ magazine contacted C.R. Snyder, the most influential psychologist currently studying the psychology of hope. The editors wanted to conduct an annual survey of hope in the American workplace. A survey of 125 companies ranging in size from 8 to 40,000 employees was completed in 2001.

The top ten companies ranked in terms of employee hopefulness had certain characteristics in common. Employees and management shared in the creation of goals, which helped everyone identify with them. The CEOs not only do not act as autocrats, they go to special lengths to make themselves approachable. Administrators showed respect for employees, and demonstrated that they cared not only about employee job performance but also about their worker's personal lives. The companies encouraged independent thought and creative problem solving. The positive and hopeful cultures that 
these companies have nurtured has resulted in one additional shared characteristic-they are all financially successful and report strong growth prospects.16

\section{$\underline{\text { Optimism }}$}

Conceptually, hope and optimism are closely related, but the subtle difference is that hope expectancies are internally focused on one's own abilities while optimism is a belief that positive outcomes will occur regardless of one's ability, thus giving optimism more of an external focus. Like hope, optimism has important implications for the way librarians approach their work. For example, in a study of how optimism moderates the negative effects of work problems on self-esteem, data was gathered from 104 female executives. Optimistic women possessed higher levels of self-esteem than women low in optimism. As the number of daily problems increased in frequency, women with higher optimism exhibited a slower decrease in self-esteem. Highly optimistic women were less likely to experience symptoms of burnout. Having an optimistic outlook thus has a positive effect on health and enables employees to remain committed to their work under difficult conditions. Women who were optimistic utilized coping strategies that involved seeking advice from colleagues about how to handle work problems, expressing their concerns about the situation to others, or simply accepting the situation and trying to learn from it. By contrast, less optimistic women used coping strategies that involved withdrawal, distancing, and self-reproach.18 Overall, optimistic women executives had the lowest stress scores in the sample, thus suggesting that optimism is an effective tool for coping with adverse work conditions. 
In another interesting study of how optimism affects work performance, Martin E.P. Seligman, a psychologist who is considered one of the founders of positive psychology, identified one particular occupation -life insurance sales- as a good test of the role of optimism on the job. Selling life insurance requires agents to repeatedly make cold calls to prospects and to continually experience disappointing responses from potential customers who have no interest in the product, resulting in high turnover and huge losses for insurance companies that spend millions of dollars orienting and training new agents.

Seligman conducted a basic correlational study of 200 Metropolitan Life agents to see if sales success was related to level of optimism. The results of this pilot study indicated that the most optimistic agents sold 37 percent more insurance than pessimists, and agents who scored in the top 10 percent sold 88 percent more.19 The author theorized that the successful agents had an optimistic explanatory style that consisted of highly positive self-talk that agents would engage in to prevent themselves from getting discouraged while making calls. They attributed unsuccessful calls to minor, temporary reasons that allowed them to move on to the next prospect without getting discouraged. Unsuccessful agents would engage in negative self-talk that would attribute their lack of success to personal flaws, obstacles they viewed as permanent and pervasive. The positive psychology of the successful agents made a significant difference not only in sales performance but also in who ultimately survived, since many of the agents who scored low in optimism eventually left the field. Seligman concluded that the most important reason that optimism affects work performance is that it generates persistence in employees which then helps them to be successful.20 
Optimism plays an important role not only in work performance but also in leadership. In a study of 64 ROTC cadets attending a U.S. Army leadership training program, officers and peers were asked to rate cadets on their leadership potential. Cadets who scored highest on optimism scales were rated as having greater potential for being successful leaders than cadets who appeared less optimistic. Being confident about the outcomes of one's behavior conveys an impression of competency to followers and to observers. Optimism contributed not only to the cadet's image of being a leader but also to the cadet's actual performance. In stressful situations, optimistic individuals will be less prone to anxiety which allows them to make better judgments, analyze problems better, and execute more complex decisions. Optimism on the part of a leader may contribute to follower's levels of confidence and to their aspirations as well.21

The relationship between optimism and leadership was further demonstrated in a study of optimism and pessimism among business leaders. Forty-eight high-level executives employed by mid- to large-size manufacturing firms were given two surveys which measured their levels of optimism and pessimism. The researchers found that the business leaders had lower pessimism scores than the norm. Interestingly, not only did the executives score lower on pessimism, so did the employees that directly reported to them. This suggests that the optimism exhibited by the leaders may have had an influence on their subordinates. 22

From these studies, it can be seen that there are clear advantages to cultivating optimism among academic library staff. Contrary to popular wisdom, optimism is not a personality trait that one is born with. It can be learned. Psychologists have found that the degree of optimism or pessimism a person possesses is primarily a function of 
cognitions. The thoughts that a person thinks affect how a person feels. Negative, pessimistic thoughts contribute to a pessimistic outlook, just as positive thoughts contribute to an optimistic one.

Through a process of cognitive retraining, psychologists have been able to help people become more optimistic. Individuals are first taught to identify negative, selfdefeating beliefs that are triggered by adverse or stressful situations at work. A librarian working at the reference desk who is experiencing difficulty answering a patron's question might think, for example, that "I am just not cut out for this work," or "I am never going to be able to find the answer." Pessimistic individuals tend to think such thoughts automatically and repeatedly.

The second step is to teach the person to examine the evidence in order to gauge the accuracy of the belief. The person is taught how to look at each thought objectively and scientifically. In the process, these thoughts are revealed to be irrational, illogical, exaggerated, and presumptuous. The person is taught to create alternative explanations that might fit the evidence. The final step is to dispute the beliefs and replace them with more positive, constructive thoughts. Psychologists have developed an ABCD model, to treat pessimistic thinking. "A" stands for the adverse situation that triggers the thoughts, "B" stands for the resulting negative beliefs, "C" represents the consequences of those beliefs, including any negative emotions or behavior that might result, and " $\mathrm{D}$ " stands for dispute and de-catastrophize, in which the person learns to challenge the negative thoughts.23 By using this model, people have been taught how to change their thought patterns from negative to positive. Academic libraries could establish training programs 
or conduct workshops as part of professional development so that staff could be trained to think positively.

\section{$\underline{\text { Subjective Well-Being }}$}

Although subjective well-being comes close to what we colloquially refer to as "happiness," it is psychologically a more complex construct. Subjective well-being encompasses not only people's thoughts but also their feelings. It refers not so much to the actual conditions of their lives as to how they regard their lives. Psychologists have found that people who feel good about their lives in general are more likely to feel good about their work.24 This suggests that academic library administrators need to look at lifestyle issues like work-family balance, telecommuting, and virtual meetings. This is particularly important as the academic library moves toward a 24/7 environment in which service demands have the potential to blur work and non-work boundaries.

Subjective well-being at work has also been associated with a psychological state that psychologists refer to as "flow."25 It can be defined as a total state of absorption in which a person becomes so immersed in the particulars of his or her job that all sense of external activities and even the passage of time is lost. The person feels challenged by the task and feels that he or she is in possession of the skills to manage it. All other past and future concerns disappear as the person's attention is solely fixed in the present moment. Attention is narrowed and concentration intensifies as one focuses on the task to be accomplished. This results in feelings of satisfaction, creativity and happiness, an overall experience of well-being and fulfillment. 
This description of the flow experience may bring to mind a passionate painter standing before a canvas, an Olympic athlete at the end of a diving board, or a Nobelcaliber astrophysicist working on a problem. But flow is experienced by all kinds of people from all walks of life. In a study of 107 employees recruited from five large Chicago companies, subjects were given beepers that were activated randomly over the course of a week. Participants were asked to fill out a self-report immediately after each beep which recorded their activity and measured the extent to which they had entered the flow state. Interestingly, the results indicated that respondents were much more likely to experience the flow state at work than during leisure pursuits. Managers and engineers experienced the flow state more than workers in other fields, perhaps because those jobs are more complex and flexible, which allows workers to regulate their challenges to support flow.26

Of particular interest to academic librarians is the growing number of studies that suggest that using information technology contributes to flow. The librarian who experiences a feeling of control when using the computer, whose attention is focused on interacting with the machine, who experiences a heightened curiosity about the information being conveyed, and who finds the interaction intrinsically interesting can easily enter a flow state. Computers readily provide the librarian with a feeling of control because they respond readily to feedback from the user and are easily modifiable and flexible. The computer screen helps to focus the librarian's attention and relegate competing stimuli to the background. Color and graphics heighten the sensory curiosity of the librarian, and menus featuring multiple options encourage the librarian to explore and experiment. 27 
Searching on the web is the kind of challenging, goal-oriented activity that is conducive to flow. In a survey of 304 frequent web users, the most frequently reported activity which led users into the flow state was searching for information. 28 The process of following hypertext links that successively lead to more information and related links makes it easy for a user to become interested and engrossed. The researcher is never quite sure what will be encountered as a result of the next click. Sifting through the mass of results in an effort to find the most relevant information can be highly absorbing. Composing and reading email messages is another internet-based activity that users mentioned as being inherently absorbing. Creating and maintaining web pages was also mentioned by respondents as being conducive to experiencing flow, perhaps because working with hypertext markup language is highly detailed work that monopolizes all the attentional resources of the user.

If flow leads to increased concentration and engagement among librarians, it would be advantageous for academic libraries to maximize the conditions that are conducive to flow in the library environment. Supervisors can encourage flow by making sure that goals are clear, and that skills are well matched to challenges. Eliminating as many distractions for staff as possible will help to elicit flow. Distractions include paperwork, bureaucracy, and micromanaging. Establishing clear priorities so that librarians are not distracted by wondering which task to begin first is important. If deficiencies in skills become evident, holding workshops can fill knowledge gaps. Feedback should be informative rather than disparaging. High expectations for staff performance should be balanced by high levels of support and concern for them. The greater the demands that are placed on librarians, the more freedom and flexibility they 
should be allowed to realize them. To the extent that it is possible, librarians should be given enough leeway to follow their interests and talents. 29

Some educators have suggested that it might make sense for faculty to abandon the traditional generalist model of teaching, research and service. Many librarians in academe are subject to faculty or quasi-faculty models of promotion and tenure so this would apply to them as well. In place of striving to be jack of all trades, facultyincluding library faculty—might choose an area of particular interest—library instruction, research and scholarship, or community involvement. Librarians who chose to specialize in one of these areas would be evaluated primarily on the basis of their accomplishments in that realm. With librarians able to focus on their area of greatest interest, productivity would likely increase, as would mastery and achievement. Those librarians who occasionally desire to switch from one path to another should be given the flexibility to do so.30 The ultimate objective would be to maximize the chances for librarians to achieve a state of flow and the enhanced performance and productivity that accompanies it.

$\underline{\text { Emotional Intelligence }}$

Emotional intelligence can be considered a positive psychology construct. Unlike traditional notions of intelligence such as IQ, which have been conceived of as fixed and deterministic, it is an ability that can be developed. It is therefore more hopeful and promising. Emotional intelligence, which is generally defined as the ability to understand and manage one's own emotions and those in others, has in recent years been viewed as 
an increasingly important factor in determining whether or not a person is successful at work.31

Traditional IQ, the ability to understand, think, and conceptualize, is no longer considered the sole determinant of success in one's chosen field. The ability to empathize, motivate, and relate are important skills increasingly valued in the workplace. They all require levels of emotional understanding and control that fall under the category of emotional intelligence. In a study of researchers at Bell Labs, investigators wanted to determine what it was that made some researchers star performers, while others were less successful. Since traditional intelligence is a prerequisite for admission to the prestigious labs, the investigators wanted to determine what other factors might account for the success of certain individuals. What the investigators found is that it is not cognitive skills that determine the success of star researchers. The researchers are only expert in a limited area and work in teams. Their success hinges on convincing their colleagues to work collaboratively with them on projects.32 Star researchers excel at creating networks of fellow experts to whom they can then turn when they need help on a project. Less popular and more disagreeable researchers were ultimately less successful at accomplishing tasks because they were unable to muster enough support from colleagues.

Academic librarianship has traditionally been regarded as a field heavily dependent on cognitive skills. Reference work, library instruction, collection management, cataloging, and other basic activities are highly intellectual processes that often require extensive thinking and reasoning when performed at a high level of proficiency. Many librarians would agree that such activities cannot be done well 
without substantial training and experience. Yet it is easy to overlook the fact that some of these functions, particularly in the area of public services such as reference work and instruction, may also require considerable emotional skill. Working with patrons at the reference desk who may be anxious, irritable, naïve, manipulative, shy or otherwise difficult to interact with may require levels of empathy, confidence, and emotional control from librarians that may sometimes be as vital to the transaction as purely cognitive skills. Emotional intelligence is also important in classroom situations in which the librarian who is teaching needs to be keenly aware of the emotional state of the students. Is the student in the third row not grasping the concept the librarian is attempting to convey, or merely bored? And what about the student who is fixated on the monitor in front of her; is she mesmerized by the librarian's teaching or is she daydreaming? 33 Librarians need to be able to interpret and act on what are often subtle emotional cues.

This is not only the case when librarians are interacting with the public, but also with their colleagues. Academic libraries increasingly rely on teams to accomplish tasks, and teamwork calls for interacting with colleagues. Collaboration on group projects requires empathy, humility, and flexibility on the part of individual team members if the group is going to achieve consensus and move forward. Conflicts sometimes arise in working with colleagues, and tact and sensitivity are necessary to overcome differences of opinion. Like the researchers at Bell Labs, emotionally intelligent librarians need to cultivate relationships and build networks of support that enable them to get their work accomplished. 
Given that emotional intelligence, unlike IQ, can be learned, can librarians improve their emotional intelligence? To begin with, it is first necessary to understand what it takes to do one's job exceptionally well. It is possible to determine this by looking at exemplary colleagues in one's specialization. If one is a subject librarian, who are the great subject librarians and what emotional skills and behavioral competencies do they possess? The next step is to be aware of one's own emotional weaknesses and limitations. What needs to be improved? It can sometimes be difficult to be accurate and objective about one's self, so it may help to solicit input from colleagues.34

Once emotional weaknesses have been identified, the librarian needs to create an action plan that will specifically address particular limitations from whatever level of emotional development the librarian happens to be. Some individuals will have a higher level of emotional sophistication than others, so the plan needs to be customized to meet the particular person's needs. Larger emotional regulation objectives, such as becoming more empathetic to the needs of colleagues, need to be broken down into smaller methodical steps, e.g. "I will listen for several minutes before interrupting a colleague." Creating a series of smaller steps makes change easier to manage and is more likely to lead to success. It helps to keep in mind that there may be occasional relapses in which a librarian may revert to old habits. If these are viewed as temporary setbacks that provide the librarian with an opportunity to learn, they will be less likely to result in discouragement. It helps to keep a record of one's progress, which can take the form of a $\log$ that tracks triumphs or setbacks in one's emotional growth.

At an administrative level, training workshops in emotional intelligence for supervisory personnel can be arranged so that librarians in management are trained in 
how to relate well to staff and patrons. Administrative personnel can be evaluated for emotional competence, including how well they relate to and motivate their staff. Once managers become aware that emotional intelligence is being taken seriously enough to be included in their evaluation, they will be more likely to take it seriously themselves. Finally, it would be valuable to include pre and post-training assessments to evaluate the impact of emotional intelligence on job performance. 35

\section{$\underline{\text { Resilience }}$}

Resilience may be considered an additional aspect of positive psychology because it can be defined as positive adaptation to change, adversity, or risk. Resilient individuals are those who manage to endure through difficult circumstances and somehow manage to always bounce back even though they have experienced illness, misfortune, or defeat in some way. Some people even seem to thrive on adversity. Each of us has encountered people who have managed to persevere through difficult situations. Psychologists have studied why it is that some individuals seem more resistant to life's travails and have increasingly come to view it as a state-like capability that can be developed.

Developing resilience is increasingly important to academic libraries and librarians because of the rapid rate of change and upheaval that is occurring in the field. The growth of information, the pace of technological change, and the increasing demands for service have made it difficult to keep up with new developments. Academic libraries now operate in a highly competitive environment in which they no longer appear to have a monopoly on information resources. As libraries struggle to keep up with change and 
remain valuable to their constituents they need to be resilient, which means that they need to employ resilient librarians.

Resilient librarians are able to adapt more easily to change because they view it as an opportunity to learn and grow, rather than as a threat. They can also be characterized as realistic optimists. These are individuals who look forward to a positive future, but do not shrink from hard realities. They prepare themselves for any eventuality, even though they hope for a positive outcome. They are positive without being naïve. Individuals high in resilience are able to find meaning and purpose even under the most difficult circumstances. They create psychological constructs that help them make sense of difficult situations and avoid feeling victimized. These constructs serve as a hopeful bridge to the future and also help to make the present more bearable. Resilient individuals are also highly resourceful and inventive. They are able to improvise solutions to make the most of what they have. In order to leverage this talent, libraries wishing to become more resilient need to empower their librarians to do whatever it takes to get the job done. Whether that means making a long-distance call to obtain some critical reference information or hand delivering a crucially needed article, librarians should be given the flexibility to improvise on the spot if it is called for.36 The ability to go "above and beyond the call" and exercise professional judgment should be a cornerstone of the resilient library's policy and culture. This kind of adaptiveness can help the library survive in novel service situations and may result in much more satisfying end-user outcomes than standardized responses such as "Would you like to speak to my supervisor?" 
Academic libraries can cultivate resilience in librarians by offering training on how to take advantage of change. Librarians who exhibit high degrees of flexibility and risk taking should be rewarded. Administrators must be open to fresh, creative approaches to problems. Whenever possible, librarians should be allowed to participate in management, and any redeployment of staff should only be done in consultation with those who may be reassigned. Adequate training and support should be provided for those who move to new positions or who initiate new programs or services.37

The latitude that librarians have should gradually be expanded. Supervisors should try to delegate as much decision making as possible and eliminate approval forms and signatures wherever feasible. Librarians should engage in virtual role-taking so that each librarian can understand all the roles in the department well enough to understand how the entire department functions and can take on other roles if necessary. Rigid organizational structures that reinforce tight decision control should be dismantled. Information channels should be opened as much as possible, so that librarians can make independent, informed decisions when the need arises without having to consult supervisors.38 This kind of resilient organizational arrangement will encourage resilient behavior among librarians.

\section{$\underline{\text { Conclusion }}$}

This study suggests that academic libraries have much to gain by establishing a positive environment though the utilization of positive psychology. Numerous benefits accrue to those libraries that foster a positive atmosphere in which librarians can feel good about themselves, their work, and their future. It has been suggested that positive 
librarians perform better on the job and are more enthusiastic, better at thinking, remembering, decision making, and at problem solving. They are more persistent and resourceful in stressful situations because they believe they will be successful. Librarians with a positive orientation also tend to have lower rates of absenteeism and lower turnover than their less positive counterparts.

Positive librarians have a positive effect on their colleagues. They are viewed by their colleagues as being more attractive interpersonally. Colleagues regard them as more socially desirable. Because they tend to relate well to others at work, they are often socially influential. They are better able to garner the trust and support of their fellow librarians, which can be extremely important for teamwork and group efforts on collaborative projects. Coworkers are more likely to say "yes" to positive librarians because they are inclined to like them and want to maintain a good relationship with them. There may also be a degree of reciprocity involved to the extent that positive librarians are likely to affirm initiatives originating with colleagues, making colleagues more likely to return the favor.39

If engendering positive feelings in employees results in happier and more productive librarians, then it is clearly in the best interest of academic library administrators to do as much as possible to create a positive environment. This can be accomplished by engaging in positive management practices. Librarians should know what is expected of them on the job. They should have adequate equipment and training to allow them to perform optimally. Each librarian should be working in the position they are best qualified to do. Librarians should receive frequent recognition from administrators that they are doing good work. Supervisors need to care about their staff 
not just as employees but also as people and be concerned about their overall development and well-being, both at and beyond the workplace.

In order to further cultivate a positive environment in the library, librarians must be made to feel that their opinions count. This means that management must make a genuine attempt to not only listen to staff, but also to follow through on what they have heard and make any necessary changes in policy and procedures. Higher-level administrators - deans and associate deans_-should articulate a vision for the library that is clear and compelling enough that each librarian feels that they have an important role to fulfill in contributing to the overall mission. The performance of quality work should be promoted not by criticism and negativity on the part of supervisors but by emphasizing employee strengths and building on them. As much as possible, competition among librarians should be discouraged and cooperation and teamwork emphasized. Each librarian should be frequently apprised of their development and progress in meeting goals. There should be continual opportunities to learn new skills through workshops, guest speakers, and similar events. Finally, staff should be surveyed on a regular basis to determine sources of employee satisfaction and dissatisfaction.40 Supervisors must be evaluated on how effectively they address employee problems identified by the survey.

In a more general sense, the library profession can learn much from emulating positive psychology, both in its science and in its practice. The shift away from problems and to strengths that is occurring in the field of psychology holds considerable promise for librarianship as well. It may be time to examine how we can strengthen individual well-being, resilience, hopefulness, and creativity in librarians so that not only will academic libraries benefit, but ultimately, those who use them. 


\section{$\underline{\text { Notes }}$}

1. Kevin Rathunde, "Toward a Psychology of Optimal Human Functioning: What Positive Psychology Can Learn from the "Experimental Turns” of James, Dewey and Maslow," Journal of Humanistic Psychology (Winter 2001): 135-153.

2. Jennifer K. Ruark, "Redefining the Good Life: A New Focus in the Social Sciences," Chronicle of Higher Education (February 12, 1999): 13-15.

3. Corey L.M. Keyes and Jonathan Haidt, "Well-Being in the Workplace and Its Relationship to Business Outcomes: A Review of the Gallup Studies," in Flourishing: Positive Psychology and the Life Well-Lived, ed. Corey L.M. Keyes and Jonathan Haidt (Washington, D.C.: American Psychological Association, 2003), 215.

4. Some examples from a recent search of the Library Literature database include: Mary Pelzer Hudson, "Conflict and Stress in Times of Change,” Library Management v.13, no.4 (Fall 1999): 224-8; Deborah F. Sheesley, "Burnout and the Academic Teaching Librarian: An Examination of the Problem and Suggested Solutions," The Journal of Academic Librarianship v.27 no.6 (November 2001): 447-451; Catherine E. Edwards, "Change and Conflict in the Academic Library," Library Management v.21 no.1 (2000): 35-41; Jamie Green, “In the Librarian's Chair: An Analysis of Factors Which Influence the Motivation of Library Staff and Contribute to the Effective Delivery of Services," Library Review v. 49 no. 8 (2000): 380-6; Melanie L. Freese, "Fostering Communication and Understanding at Hofstra University's Axinn Library," PNLA Quarterly v.66 no.3 (Spring 2002): 6-8; JoAnne Deeken, "Tact and Tenacity: Dealing with Difficult People at Work," 
The Serials Librarian v.42 no. $3 / 4$ (2002): 299-304; Thomas Wilburn Leonhardt,

"Behind the Scenes: Watching for Warning Signs of Trouble," $\underline{\text { Technicalities }}$ v.22, no.3 (May/June 2002): 12-13.

5. Fred Luthans, "Positive Organizational Behavior: Developing and Managing Psychological Strengths," Academy of Management Executive v.16 no.1 (February 2002): 57-72.

6. Albert Bandura, "Self-Efficacy: Toward a Unifying Theory of Behavioral Change," Psychological Review v.84 no.2 (March 1977): 191-215.

7. James E. Maddux, "Self-Efficacy: The Power of Believing You Can," in Handbook of Positive Psychology, ed. C.R. Snyder and Shane J. Lopez (New York: Oxford University Press, 2002), 282.

8. Michael P. Leiter, "Burnout As a Crisis in Self-Efficacy: Conceptual and Practical Implications," Work \& Stress v.6 no.2 (April-June 1992): 107-115.

9. Tracy McDonald and Marc Siegall, "The Effects of Technological Self-Efficacy and Job Focus on Job Performance, Attitudes and Withdrawal Behaviors," Journal of Psychology v.126 n.5 (September 1992): 465-475.

10. H.W. Chou, "Effects of Training Method and Computer Anxiety on Learning Performance and Self-Efficacy," Computers in Human Behavior v. 17 no.1 (January 2001): 51-69.

11. Albert Bandura, "Cultivate Self-Efficacy for Personal and Organizational Effectiveness," in The Blackwell Handbook of Principles of Organizational Behavior ed. Edwin A. Locke (New York: Oxford University Press, 2000), 122. 
12. L.M. Irving, C.R. Snyder, and J.J. Crowson, "Hope and Coping with Cancer by College Women,” Journal of Personality v.66 no.2 (April 1998): 195-214.

13. Lewis A. Curry, C.R. Snyder, David L. Cook, Brent C. Ruby and Michael Rehm, "Role of Hope in Academic and Sport Acheivement," Journal of Personality and Social Psychology v.73 no.6 (December 1997): 1257-1267.

14. Bret L. Simmons and Debra L. Nelson, "Eustress at Work: The Relationship between Hope and Health in Hospital Nurses," Health Care Management Review v.26 no.4 (Fall, 2001): 7-18

15. Stuart A. Kirk and Gary E. Koeske, "The Fate of Optimism: A Longitudinal Study of Case Manager's Hopefulness and Subsequent Morale," Research on Social Work Practice v.5 no.1 (January 1995): 47-61.

16. Virgil H. Adams, C.R. Snyder, Kevin L. Rand, Elisa A. King, David R. Sigmon, and Kim M. Pulvers, "Hope in the Workplace," in Handbook of Workplace Spirituality and Organizational Performance, ed. by Robert A. Giacalone and Carole L. Jurkiewicz (New York: M.E. Sharpe, 2003), 374.

17. Anthony Scioli, Christine M. Chamberlin, Cindi M. Samor, Anna B. La Pointe, Tamara L. Campbell, Alex R. Macleod, and Jennifer McLenon, “A Prospective Study of Hope, Optimism, and Health," Psychological Reports v.81 no.3 (December 1997): 723-733.

18. P.S. Fry, "Perfectionism, Humor, and Optimism as Moderators of Health Outcomes and Determinants of Coping Styles of Women Executives," Genetic, Social, and General Psychology Monographs v.121 no.2 (May 1995): 213-245. 
19. Martin E.P. Seligman, Learned Optimism (New York: Alfred A. Knopf, 1991), 99.

20. Seligman, 104.

21. Martin M. Chemers, Carl B. Watson, and Stephen T. May, "Dispositional Affect and Leadership Effectiveness: A Comparison of Self-Esteem, Optimism, and Efficacy," Personality and Social Psychology Bulletin v.26 no.3 (March 2000): 267-277.

22. Lisa J. Wunderley, W. Brendan Reddy, and William N. Dember, “Optimism and Pessimism in Business Leaders," Journal of Applied Social Psychology v.28, no.9 (May 1998): 751-760.

23. Peter Schulman, "Applying Learned Optimism to Increase Sales Productivity," Journal of Personal Selling \& Sales Management v.19 no.1 (Winter 1999): 31-37.

24. Timothy A. Judge and Charles L. Hulin, "Job Satisfaction as a Reflection of Disposition: A Multiple Source Causal Analysis," Organizational Behavior and Human Decision Processes v.56 no.3 (December 1993): 388-421.

25. Ed Diener, "Subjective Well-Being: The Science of Happiness and a Proposal for a National Index," American Psychologist v.55, no.1 (January 2000): 34-43.

26. Judith Le Fevre, "Flow and the Quality of Experience During Work and Leisure," in Optimal Experience: Psychological Studies of Flow in Consciousness, ed. by Mihaly Csikzentmihalyi and Isabella Selega Czikszentmihalyi (New York: Cambridge University Press, 1988), 317. 
27. Jane Webster, Linda Klebe Trevino, and Lisa Ryan, "The Dimensionality and Correlates of Flow in Human-Computer Interactions," Computers in Human Behavior v.9 no.4 (Winter 1993): 411-426.

28. Hsiang Chen, Rolk T. Wigand, and Michael Nilan, "Exploring Web Users' Optimal Flow Experiences,” Information Technology \& People v.13 n.4 (2000): 263-281.

29. Samuel Whalen, "Flow and the Engagement of Talent: Implications for Secondary Schooling,” NASSP Bulletin v.82 n.2 (February 1998): 22-37. 30. Myles Brand, "Changing Faculty Roles in Research Universities: Using the Pathways Strategy," Change v. 32 no.6 (November/December 2000): 42-45.

31. Peter Salovey, John D. Mayer, and David Caruso, "The Positive Psychology of Emotional Intelligence," in Handbook of Positive Psychology, ed. by C.R. Snyder and Shane J. Lopez (New York: Oxford University Press, 2002), 159.

32. Robert Kelley and Janet Caplan, "How Bell Labs Creates Star Performers," Harvard Business Review v.71 no.4 (July/August 1993): 128-139.

33. Julianne C. Turner, "Discovering Emotion in Classroom Motivation Research," Educational Psychologist v.37 no.2 (Summer 2002): 107-115.

34. Audrey M. Korsgaard, "The Impact of Self-Appraisals on Reactions to Feedback From Others: The Role of Self-Enhancement and Self-Consistency Concerns," Journal of Organizational Behavior v.17, no.4 (July 1996): 301-311.

35. Daniel Goleman, Working with Emotional Intelligence (New York: Bantam Books, 1998), 277. 
36. Diane L. Coutu, "How Resilience Works," Harvard Business Review v.80 no.5 (May 2002): 46-55.

37. Peggy J. Doe, “Creating a Resilient Organization,” Canadian Business Review v.21 no.2 (Summer 1994): 22-25.

38. Larry Mallak, "Putting Organizational Resilience to Work,” Industrial Management v.40 no.6 (November/December 1998): 8-14.

39. Barry M. Staw, Robert I. Sutton, and Lisa H. Pellard, "Employee Positive Emotion and Favorable Outcomes at the Workplace," Organization Science v.5 no.1 (February 1994): 51-71.

40. J.K. Harter, F.L. Schmidt, \& T.L. Hayes, "Business Unit-Level Relationship Between Employee Satisfaction, Employee Engagement, and Business Outcomes: A Meta-Analysis," Journal of Applied Psychology v.87 no.2 (April 2002): 268279. 